\title{
A conservative approach for treating excessive gingival display: a clinical report
}

\begin{abstract}
Excessive gingival display (EGD) namely "the gummy smile" is unattractive smile for some patients. These patients seek treatment and request an attractive smile in dental clinics. The excessive gingival display could be a result of multiple factors and usually its treatment with orthognathic surgery is aggressive and has high morbidity rate.
\end{abstract}

Aim: The aim of this clinical report is to present a conservative and combined treatment approach to a case with an excessive gingival display of multiple etiologies.

Materials and methods: The patient had EGD due to vertical maxillary excess and hypermobile upper lip. The preferred treatment was conservative with minimal side effects. The management began with aesthetic crown lengthening conducted with osteotomy and buccal bone re-contouring. Then, after 6 months the patient underwent a lip repositioning surgery.

Results: Reduction of EGD and restricted muscle pull of upper lip.

Conclusion: Gummy smile can be treated conservatively with combined approach Identifying the causative factors and proper case selection are the key elements for good management.

Keywords: Gummy smile; Hypermobile lip; Lip repositioning; Vertical maxillary excess
Volume 9 Issue 2 - 2018

\author{
Bann A Al-Hazmi \\ Department of Periodontics and Community Dentistry, College \\ of Dentistry, King Saud University, Saudi Arabia
}

Correspondence: Bann A Al-Hazmi, Department of Periodontics and Community Dentistry, College of Dentistry, King Saud University, P. O. Box 60169, Riyadh II545, Saudi Arabia

Received: March 3, 2018 | Published: March 22, 2018

\section{Introduction}

Excessive gingival display (EGD) is one of the major causes of patient embarrassment. An imbalance in the gingiva-tooth ratio results in dominance of gingival appearance often referred to as "gummy smile." A normal gingival display between the inferior border of the upper lip and the gingival margin of the central incisors during a normal smile is $1-2 \mathrm{~mm}$. Whereas, excessive gingivae-to-lip distance of $3 \mathrm{~mm}$ or more is considered as unattractive. ${ }^{1} \mathrm{~A}$ gummy smile is prevalent in $10.5-29 \%$ of the population..$^{2}$ It is highly prevalent among women and the excessive gingival exposure decreases with age due to loss of muscle tone in both upper and lower lips. ${ }^{3}$ Gummy smile has a variety of possible etiologies that can act alone or in combination. First, it may be a result of delayed eruption in which the gingiva fails to complete the apical migration over the maxillary teeth to a position that is $1 \mathrm{~mm}$ coronal to the cement-enamel junctions. ${ }^{4} \mathrm{In}$ this case of delayed tooth eruption, restoring the normal dentogingival relationships can be achieved with an aesthetic crown lengthening. ${ }^{5}$ The procedure involves moving the gingival margins apically through soft and possibly hard tissue resection. The second possible cause is gingival enlargement. ${ }^{2}$ Gingival enlargement could be due to dental plaque, hereditary gingival fibromatosis, medications or hormonal changes. ${ }^{6,7}$ The management depends on periodontal therapy to remove plaque and plaque retentive factors and modification of medication regimen. Gingivectomy and gingivoplasty surgeries are possible to deal with enlarged soft tissues. ${ }^{8}$ The third possibility is vertical maxillary excess in which there is an enlarged vertical dimension of the midface and incompetent lips. ${ }^{9}$ Treatment involves orthognathic surgery. It involves hospitalization and significant morbidity for patients. The Fourth possibility is the hypermobility of upper lip caused by the lip elevator muscles. ${ }^{2}$ Botox injections may be used as a temporary solution to the problem, ${ }^{10}$ or for more stable results, surgical lip repositioning, could be utilized to reduce the labial retraction of the elevator smile muscle and minimize the gingival display. ${ }^{11}$ Finally, another cause is the deficient lip length that can be managed with lip training exercises. ${ }^{2}$ The average length of the maxillary lip is 20 to $22 \mathrm{~mm}$ in young adult females and 22 to $24 \mathrm{~mm}$ in young adult males. ${ }^{12}$

During patient examination, it is important to establish the etiology responsible for the excessive gingival display. Cases of excessive gingival display with multiple etiologies require more than one technique to achieve desirable outcomes. The aim of this clinical report is to present a conservative combined treatment approach to a case with an excessive gingival display of multiple etiologies. An aesthetic crown lengthening was performed in conjunction with lip repositioning surgery.

\section{Case report}

A forty year old woman, with no significant medical history, came to our clinic with a chief complain of an undesired gummy smile and square anterior teeth. During the clinical extra-oral examination, symmetric facial features were found with a normal upper lip length of about $20 \mathrm{~mm}$ (Figure 1A). Patient has longer lower third of the face and hypermobile upper lip that caused an excess gingival display of approximately $6 \mathrm{~mm}$ at dynamic smiling (Figure 1A) (Figure 1B). A periodontal examination revealed healthy non-inflamed gingiva with an adequate width of attached gingiva on the facial aspect and prominent canine eminence bilaterally. There was a deep bite, and the upper central incisors were not short $(9 \mathrm{~mm})$. Based on Bhola et al. classification, ${ }^{2}$ excessive gingival display was diagnosed, caused by a combination of a moderate bony maxillary excess EGD (B) degree 2, and a hypermobile lip EGD (E) subclass 2 that revealed 4 to $8 \mathrm{~mm}$ of gingiva. ${ }^{2}$ Different treatment plan options were presented to the patient. 
Patient preferred conservative and less morbidity approach to treat her gummy smile and square teeth. In order to make a final decision and to involve patient's opinion in the treatment plan, a wax- up and transparent stent of upper teeth were made. The wax-up represents the upper teeth from second premolar to collateral after aesthetic crown lengthening with $3 \mathrm{~mm}$ longer crowns (Figure 2A). Patient tried the stent and liked the future results of esthetic crown lengthening (Figure 2B). After evaluation and discussion the exact sequence of the therapy and the possible complications, the procedures of the aesthetic crown lengthening with osteotomy and lip repositioning were selected.
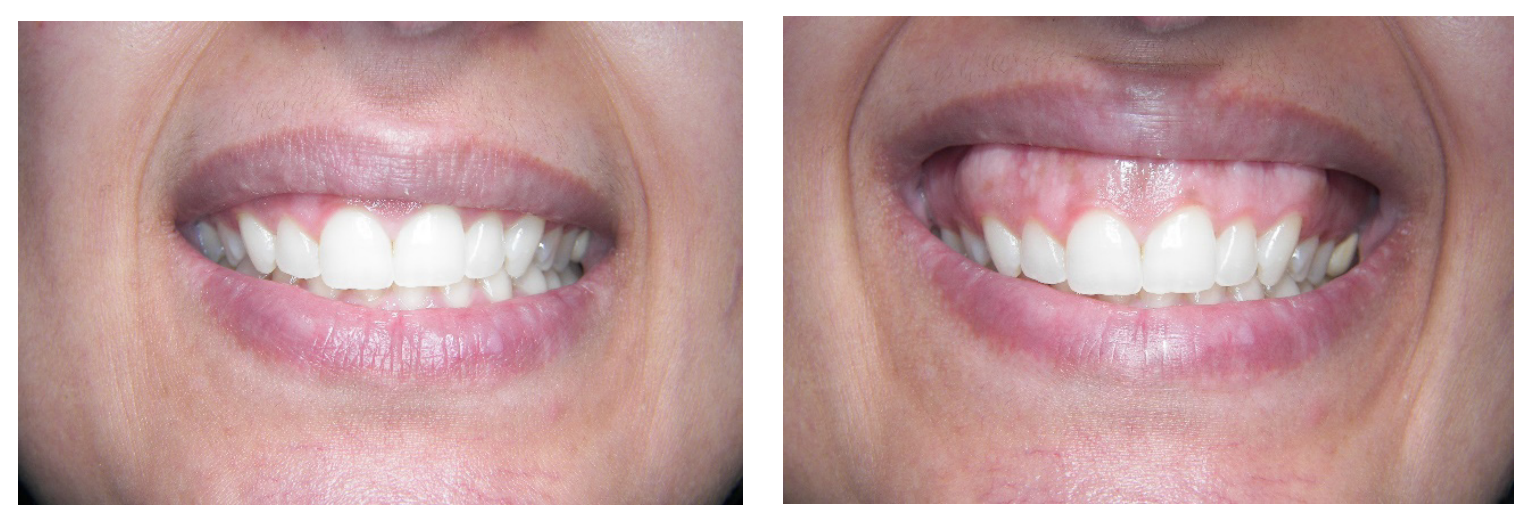

Figure I Preoperative smiles.A: Static smile; B: Dynamic smile.
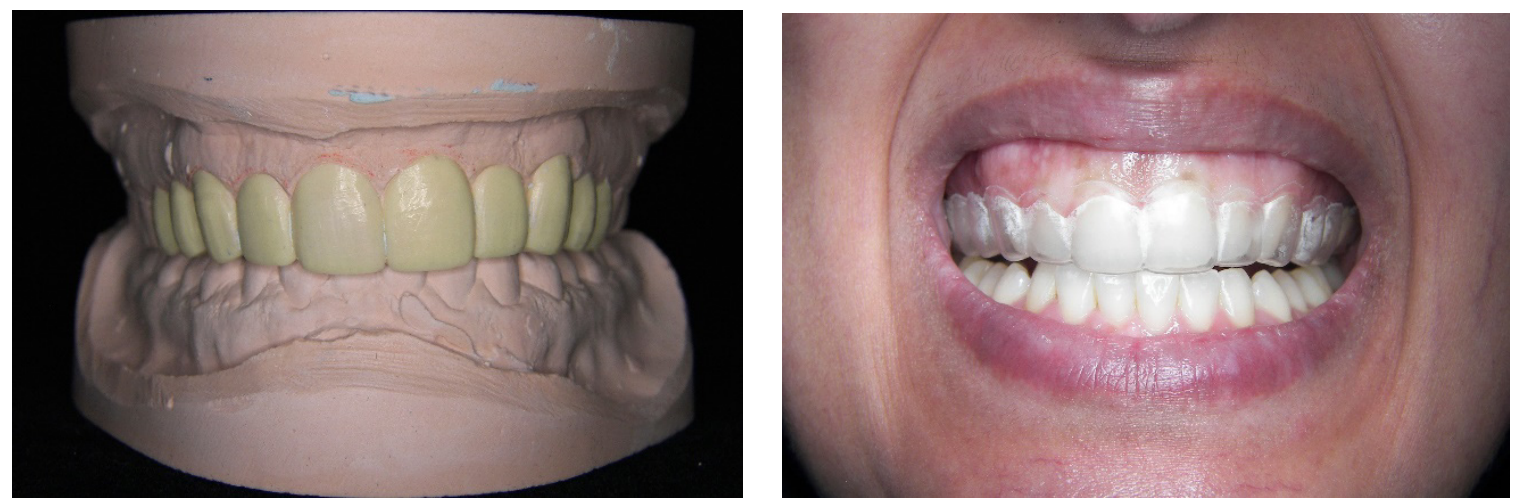

Figure 2 A: Wax-up of the upper teeth with $3 \mathrm{~mm}$ longer crowns; B: Patient is trying the upper stent that represent the final teeth shape after aesthetic crown lengthening.

\section{Surgery one (aesthetic crown lengthening)}

The objectives of aesthetic crown lengthening were to reshape the square upper teeth to a longer ones; as the shape of patient's face and to reduce from the excessive gingival exposure during dynamic smiling. Local anesthesia was given via local infiltration with Xylocaine 2\% with Adrenaline 1:80,000 (XYLOCAINE® Dental Adrenaline $2 \%, 20 \mathrm{mg} / \mathrm{ml}+12.5 \mu \mathrm{g} / \mathrm{ml}, 1.8 \mathrm{ml}$, DENTSPLY). Demarcation of cemento-enamel junction and gingivectomy were performed from second premolar to collateral via internal bevel incision. The incision line followed the cemento-enamel junction without disturbing the proximal papilla (Figure 3A). A full-thickness flap was, then, elevated from the second premolar to collateral via intra-sulcular incision (Figure 3B). An ostectomy was carried out to remove tooth-supporting bone 3 to $4 \mathrm{~mm}$ from cemento-enamel junction to re-establish the biologic width from the future gingival margins. In addition, canine eminence and buccal bone were relieved and re-contoured. The flap was repositioned at its original position and sutured using vicryle 5-0 sutures (Coated VICRYL $\AA$, polyglactin 910, Sutures, ETHICON, JOHNSON \& JOHNSON HEALTH CARE) with single interrupted sutures (Figure 3C). The postsurgical instructions included a diet of soft foods, intermittent icing of the upper lip for the first day, avoidance of tooth brushing around the surgical site, and gentle rinsing with $0.12 \%$ chlorhexidine gluconate twice daily for 14 days. Ibuprofen $400 \mathrm{mg}$ bid were prescribed for 7 days. After 2 weeks, healing was uneventful and the sutures were removed. Improvement of the gummy smile was achieved immediately (Figure 3D). At 2 months of healing, the exposed root surfaces were completely covered and final gingival margins were aesthetic and stable (Figure 3E). After 6 months, the tissue maturation was completed, and the patient was ready for the modified lip repositioning surgery. The amount of epithelium to be excised was determined by doubling the amount of gingival display. In this case, the band was approximately 10 to $12 \mathrm{~mm}$ wide.

\section{Surgery two (lip repositioning)}

Under local anesthesia Xylocaine 2\% with Adrenaline 1:80,000, the surgical area was demarcated with marker as an elliptical shape (Figure 4A). The incision outlined from right first molar to left first molar. A partial-thickness incision was made along the mucogingival junction. Second parallel incision was made at the labial mucosa at approximately $10-12 \mathrm{~mm}$ distance from the first incision (Figure 
4B) (Figure 4C). The two incisions were connected at the distal ends. The epithelium was removed in the incision outline, leaving the underlying connective tissue exposed (Figure 4D). Middle high frenum attachment was removed. Bleeding was controlled by an additional local anesthesia infiltration and the use of pressure. Care was taken to avoid damage to the muscle tissue, nerves, and any minor salivary glands in the submucosa. The parallel incision lines were approximated with interrupted stabilization sutures with, first, midline suture then, alongside the borders of the incision. These sutures were made to ensure proper alignment of the lip midline and to approximate both flap horizontal borders using Vicryl 4-0 (Figure $4 \mathrm{E})$. Other than limited facial movements during healing, postsurgical instructions and medications were the same as previously noted. The patient was seen for a follow-up at 1, 2, 6, and 12 weeks after surgery. At 1 week, healing was uneventful and mild pain and tension and moderate swelling of the upper lip were reported. At 2 weeks, the sutures were removed and the slight tension and soreness below the upper lip were reduced. The suture area of the lip repositioning healed uneventfully in the form of a scar (Figure 4F), which was not apparent when the patient smiled (Figure 5A). At 12 weeks, the patient was very satisfied with the esthetic outcome and her harmonic smile, revealing adequate gingival display and desired tooth proportion (Figure 5A) (Figure 5B).
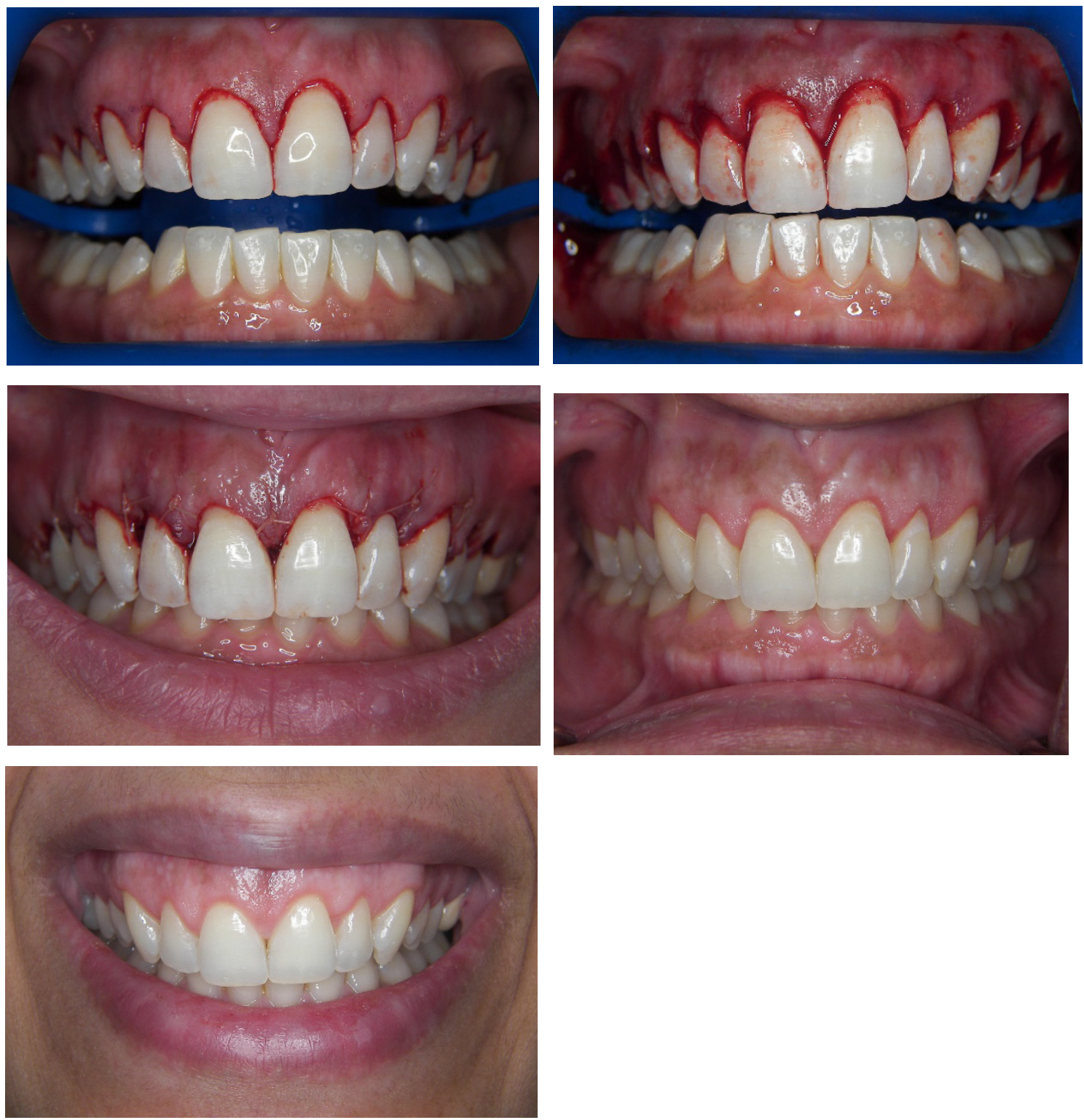

Figure 3 Aesthetic crown surgery $(E C L)$. A: Gingivectomy at upper teeth from second premolar to collateral; B: Intra-sulcular incision and full-thickness flap at upper teeth from second premolar to collateral. C: Suturing with interrupted single sutures using vicryle 5-0. D) Teeth and soft tissue at Follow-up after 2 weeks of ECL. E) Smile at follow-up after 2 months of ECL. 

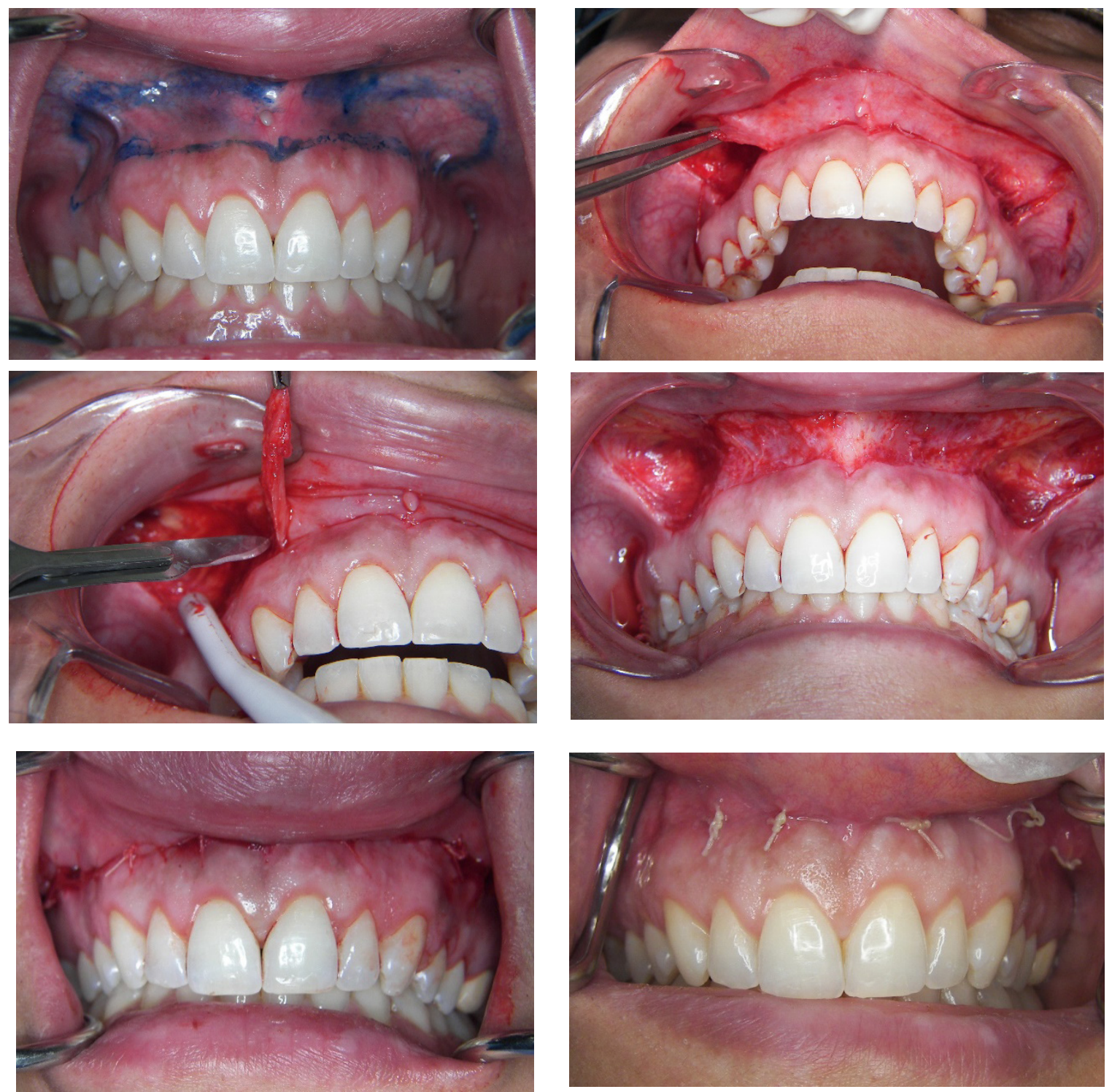

Figure 4 Lip repositioning surgery (LRP). A: Demarcation of incision outline as elliptical form; B: Partial-thickness incision was made along the mucogingival junction and labial mucosa. C: Dissection and removal of epithelium layer; D: Exposed connective tissue; $\mathrm{E}$ :Wound suturing with single interrupted sutures; $\mathrm{F}$ : Tissues healing after 2 weeks of LRP.
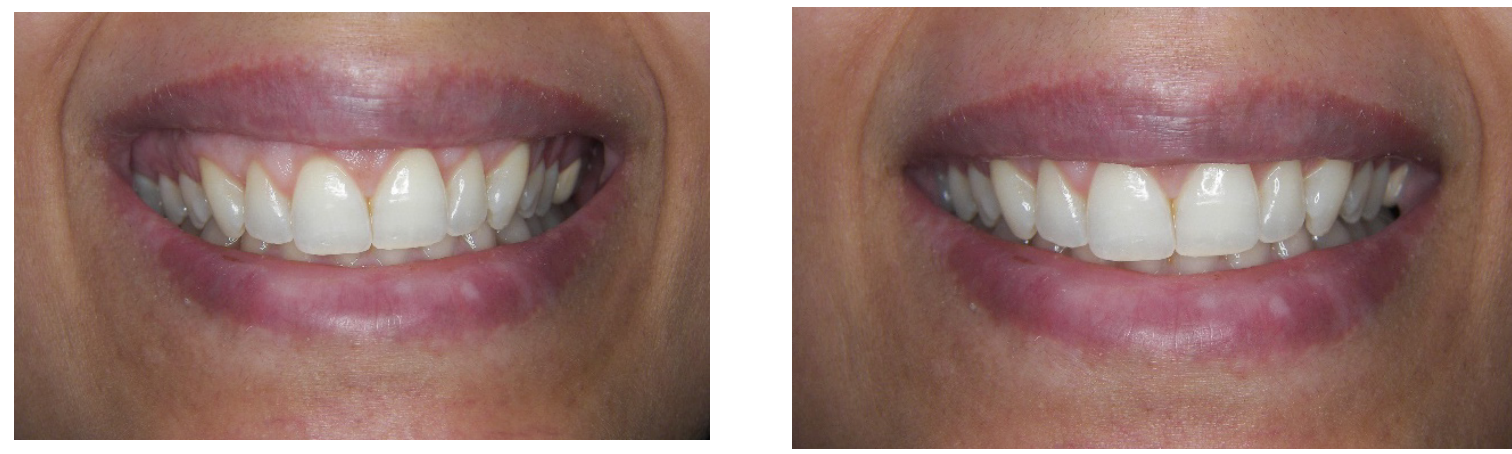

Figure 5 postoperative smiles at 12 week of lip repositioning surgery. A: Dynamic smile; B: Static smile.

Citation: Al-Hazmi BA.A conservative approach for treating excessive gingival display: a clinical report.J Dent Health Oral Disord Ther. 2018;9(2):137-I4I. DOI: 10.15406/jdhodt.2018.09.00345 


\section{Discussion}

Lip repositioning was first reported as a corrective method for a gummy smile in 1973 by Rubinstein and Kostianovsky. ${ }^{13}$ Then, a modification to the original surgical technique was introduced by Silva et al. ${ }^{14}$ who proposed maintaining the attachment of the upper maxillary frenum; this to maintain the position of the labial midline and to reduce the morbidity. The modified lip repositioning surgery is considered safer and designed to have fewer complications compared to muscle dissection and repositioning as well as orthognathic surgery. ${ }^{14}$ Complications from lip repositioning surgery can occur and include discomfort, ecchymosis, swelling of the upper lip, relapse, mucocele formation, paresthesia and an asymmetric smile. ${ }^{2}$ Relapse following lip repositioning technique was found to occur in $8 \%$ of the cases treated. ${ }^{15}$ Patient satisfaction also may be limited; at 3 months post-surgery with an average outcome of a $3-\mathrm{mm}$ gingival display, only $66 \%$ of patients were satisfied with their outcome. ${ }^{15}$ Sliva and his colleagues ${ }^{14}$ conducted a survey to evaluate patients underwent lip repositioning surgery after 2.5 years. They found that there were $90 \%$ of patients who want to repeat the procedure and $70 \%$ considered the post-operative amount of gingival display to be "about right'.

Ishida et al. ${ }^{16}$ have described a more invasive combined approach for treating excessive gingival display that included myotomy of the levator labii superioris muscle. One of the disadvantages of their technique is the high morbidity and irreversible outcome. In some other studies, ${ }^{10,17-19}$ botulinum toxin has yielded satisfactory results, given that it blocks the muscular activity. However, Botulinum toxin technique has a transitory effect (6-7 months) and for this reason, the toxin must be reapplied periodically to maintain the desired outcome. In this present case, there was a risk of root surfaces exposure after gingivectomy and osteotomy. Osteotomy was made to achieve a biological width and to create healthy aesthetic gingival margins. To avoid this problem, the interproximal papilla and its underlying bone were left unchanged. However, the minor root surfaces exposure, were covered again with gingival tissues after 2 months of soft tissue remodeling (Figure 5A) (Figure 5B). Buccal bone and canine eminence were re-contoured to minimize the bulbous appearance of the soft tissue architecture and to allow a more relaxed, fuller upper lip at smile.

\section{Conclusion}

Gummy smile can be treated conservatively with a combined approach. Identifying the causative factors and proper case selection are the key elements for good management.

\section{Acknowledgment}

None.

\section{Conflicts of interest}

There are no conflicts of interest.

\section{References}

1. Kokich VO Jr, Kiyak HA, Shapiro PA. Comparing the perception of dentists and lay people to altered dental esthetics. J Esthet Dent. 1999;11(6):311-24.
2. Bhola M, Fairbairn PJ, Kolhatkar S, et al. LipStaT: The Lip Stabilization Technique - Indications and guidelines for case selection and classification of excessive gingival display. Int J Periodontics Restorative Dent. 2015;35(4):549-559.

3. Desai S, Upadhyay M, Nanda R. Dynamic smile analysis: Changes with age. Am J Orthod Dentofacial Orthop. 2009;136(3):310.e1-10.

4. Garguilo A, Wenz F, Orban B. Dimensions and relations at the dentogingival junction in humans. J Periodontol. 1961;132(3):261-267.

5. Lee EA. Aesthetic crown lengthening: classification, biologic rationale, and treatment planning considerations. Pract Proced Aesthet Dent. 2004;16(10):769-778.

6. Del Angelo S, Murphy J, Claman L, et al. Hereditary gingival fibromatosis: A review. Comepend Contin Educ Dent. 2007;28(3):138-143.

7. Nakib N, Ashrafi SS. Drug-induced gingival overgrowth. Dis Mon. 2011;57(4):225-30

8. MGoldman H. Gingivectomy: Indications, contraindications, and method. Am J Orthodont Oral Surg. 1945;5:323-26.

9. Ezquerra F, Berrazueta MJ, Ruiz-Capillas A, et al. New approach to the gummy smile. Plast Reconstr Surg. 1999;104(4):1143-1152.

10. Suber JS, Dinh TP, Prince MD, et al. On a botulinum toxin A for the treatment of a "gummy smile". Aesthet Surg J. 2014;34:432-7.

11. Rosenblatt A, Simon Z. Lip repositioning for reduction of excessive gingival display: A clinical report. Int J Periodontics Restorative Dent. 2006;26(5):433-7.

12. Peck S, Peck L, Kataja M. The gingival smile line. Angle Orthod. 1992;62(2):92-102.

13. Rubinstein A, Kostianovsky A. Cosmetic surgery for the malformation of the laugh: Original technique [in Spanish]. Prensa Med Argent. $1973 ; 60: 952$

14. Silva CO, Ribeiro-Júnior NV, Campos TV, et al. Excessive gingiva display: Treatment by a modified lip repositioning technique. $J$ Clin Periodontol. 2013;40(3):260-265.

15. Abdullah WA, Khalil HS, Alhindi MM, et al. Modifying gummy smile: A minimally invasive approach. J Contemp Dent Pract. 2014;15(6):821826.

16. Ishida LH, Ishida LC, Ishida J, et al. Myotomy of the levator labii superioris muscle and lip repositioning: A combined approach for the correction of gummy smile. Plast Reconstr Surg. 2010;126(3):10141019.

17. Al-Fouzan AF, Mokeem LS, Al-Saqat RT, et al. Botulinum Toxin for the Treatment of Gummv Smile. J Contemp Dent Pract. 2017;18(6):474- 8.

18. Dinker S, Anitha A, Sorake A, et al. Management of gummy smile with botulinum toxin type-A: A case report. J Int Oral Health. 2014;6(1):1115 .

19. Polo M. Botulinum toxin type A (Botox) for the neuromuscular correction of excessive gingival display on smiling (gummy smile). Am J Orthod Dentofacial Orthop. 2008;133(2):195-203. 